\title{
Comparison of Upper and Lower Cervical Muscle Strengths Between Subjects With and Without Forward Head Posture
}

\author{
Ji-yeon Eun'1, PT, BPT, Oh-yun Kwon², PT, PhD, Ui-jae Hwang ${ }^{1,2}$, PT, PhD, Sung-hoon Jung ${ }^{1,2}$, PT, PhD, \\ Sun-hee Ahn ${ }^{1,2}, \mathrm{PT}, \mathrm{PhD}$
}

${ }^{1}$ Department of Physical Therapy, Graduate School, Yonsei University, ${ }^{2}$ Department of Physical Therapy, College of Health Science, Laboratory of Kinetic Ergocise Based on Movement Analysis, Yonsei University, Wonju, Korea

\author{
Article Info \\ Received October 8, 2020 \\ Revised October 26, 2020 \\ Accepted October 27, 2020 \\ Corresponding Author \\ Oh-yun Kwon \\ E-mail: kwonoy@yonsei.ac.kr \\ https://orcid.org/0000-0002-9699-768X
}

\section{Key Words}

Head

Neck

Posture
Background: Forward head posture (FHP) is common postural malalignment. FHP is described relatively extension to upper cervical and lower cervical is relatively flexion. Although several researchers mentioned the lower cervical flexion posture in FHP, most of the studies related to FHP is focused on the deep cervical flexor function.

Objects: The purposes of present study is to compare the cervical strength (upper cervical extension [UCE], lower cervical extension [LCE], upper cervical flexion [UCF], lower cervical flexion [LCF]) between individuals with and without FHP.

Methods: Fifty-one participants are recruited. Participants who have the craniovertebral angle (CVA) less than 48 degree were classified to the FHP group $(n=24)$ and the others were included in without FHP group $(n=27)$. The cervical strength (UCE, LCE, UCF, LCF) were measured using Smart KEMA strength sensor and the strength data was normalized by body weight. All strength measurement conducted at head and neck neutral position in sitting. Independent t-test was used to compare the cervical strength between individuals with and without FHP.

Results: The mean value of CVA was greater in without FHP group than with FHP group ( $p$ $<0.000)$. The strength value of UCF $(p<0.002)$ and LCE $(p<0.001)$ was significant less in FHP group than without FHP group. But no significant differences were seen in the LCF and UCE strength between two groups.

Conclusion: UCF and LCE weakness in FHP group should be considered to evaluate and manage the individuals with FHP.

\section{INTRODUCTION}

Forward head posture (FHP) is caused by improper working posture with a computer, potentially leading to changes in head and neck alignment [1]. In the sagittal plane, it has been defined when the craniovertebral angle (CVA) is less than $50^{\circ}$ [2]. FHP is associated with neck pain, temporomandibular disorder, and headache and imposes an abnormal load on the cervical muscles $[1,3]$.

FHP causes muscle imbalance in the cervical spine. Increase in FHP is associated with weakness and lengthening of the upper cervical flexor (UCF) muscles, such as the longus colli and longus capitis, and lower cervical extensor (LCE) muscles, such as the semispinalis cervicis, multifidus, and splenius cerivicis
[4]. In addition, FHP is associated with shortening of the upper cervical extensor (UCE) muscles, including the semispinalis capitis, rectus capitis, and lower cervical flexor (LCF) muscle, such as the sternocleidomastoid [5-7].

It is important to achieve a balance between the strength of the cervical flexors and extensors for managing cervical disorders with FHP [1]. Cagnie et al. [8] reported that cervical extensor strength was significantly decreased in individuals with neck pain. Bokaee et al. [1] suggested that the ratio of isometric strength between the UCF and UCE may be a good indicator for evaluating individuals with FHP. Although several researchers have reported flexed posture of lower cervical in FHP [7,9], the research on LCE strength in individuals with and without FHP, is insufficient. 
Nojiri et al. [10] found that the lower cervical region becomes kyphotic as the lordosis of the upper cervical region increases. Therefore, the lower cervical region might be considered as an element that determines the upright posture of the head with the upper cervical region. However, no study has investigated the strength of the flexors and extensors of the upper and lower cervical region in individuals with and without FHP. Therefore, the purpose of this study was to compare the strength of the flexor and extensor muscles of the upper and lower cervical regions between individuals with and without FHP. We hypothesized that the UCF and LCE strength would be lower in the FHP group than in the group without FHP.

\section{MATERIALS AND METHODS}

\section{Subjects}

The participants were recruited using a social network system. The healthy adults aged between 20 and 45 years were included, and were divided into two groups based on the CVA: those with CVA less than $48^{\circ}$ were included in the FHP group, while those with CVA greater than $48^{\circ}$ were included in the without FHP group [11]. Individuals with any pathology in the neck region and those who were unable to perform the strength test in the present study, were excluded [12]. Fiftyone subjects (age $=32.6 \pm 4.8$ years, height $=168.8 \pm 7.8 \mathrm{~cm}$, weight $=68.9 \pm 15.5 \mathrm{~kg}$ ) were recruited in this study. Twentyfour subjects (male: 15, female: 9) were included in the FHP group and 27 subjects (male: 10, female: 17) were included in the without FHP group. All participants signed an informed consent form approved by the Yonsei University Mirae Institutional Review Board (approval number: 1041849-202002-BM022-02).

\section{Procedure}

\section{1) CVA}

A mobile phone camera (iPhone; Apple Inc., Cupertino, CA, USA) was used to capture a photograph to measure the CVA. The camera was installed on the right side of the subjects at a distance of 2 meters [13]. Reflex markers were attached to the C7 spinous process and tragus of right ear, respectively. The subjects were asked to stand comfortably, with their right side toward the camera. The height of the camera was set to the subject's shoulder height [14]. After capturing a photo, a line was drawn parallel to the floor at the C7 level and another one through the tragus and C7 spinous process (Figure 1) [15]. Image J imaging software (US National Institutes of Health, Bethesda, MD, USA) was used to analyze the CVA [16].

\section{2) Strength measurement}

Isometric strength of the UCE, LCE, UCF, and LCF was measured using a Smart KEMA strength sensor (KOREATECH Co., Ltd., Seoul, Korea). One side of the sensor was fixed to an immobile bar with a nonelastic belt, and the opposite side was hung on the subject. The force signals were transmitted to an Android tablet for analysis with the Smart KEMA software, at a sampling frequency of $10 \mathrm{~Hz}$, via a Bluetooth connection. The intra-rater reliability of the strength sensor has been presented in previous studies [7,17].

The subjects sat upright in a chair with a backrest $[5,18]$. The pelvis and upper thorax were strapped to the back of the chair to stabilize the upper body while measuring the neck strength. During all strength measurements, the virtual line through the forehead and chin was perpendicular to the floor. To avoid compensatory movement, the examiner gave a verbal cue to maintain the head and trunk in a neutral position. The adjustable axis of upper cervical flexion and extension is the concha of the ear, and lower cervical flexion and extension is the transverse process of C7 [5,18]. The subjects were instructed to isometrically contract the muscles twice for 5 seconds at the maximum force and a 30-second rest was provided to avoid muscle fatigue. The application calculated the average value at middle 3 seconds, and the average of the two values was used

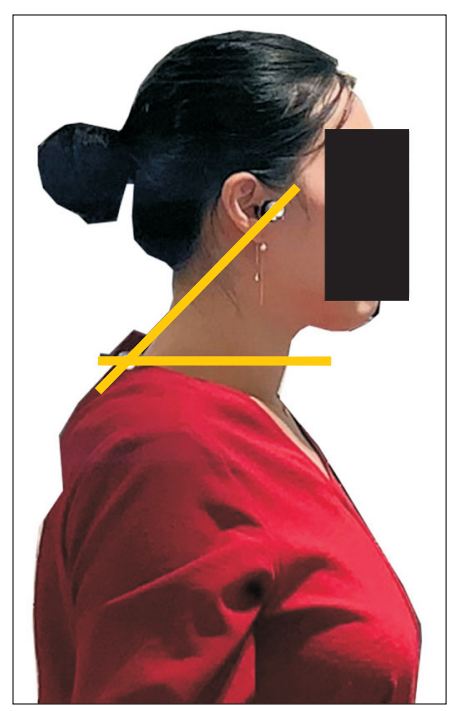

Figure 1. Craniovertebral angle. 
for data analysis. All strength data were normalized by body weight and presented in terms of percentage (\% body weight). The procedure is shown in Table 1.

\section{Statistical Analysis}

The Kolmogorov-Smirnov test was used to confirm the normal distribution. Independent t-tests were used to analyze the differences in the CVA, UCE, LCE, UCF, and LCF between groups with and without FHP. The level of statistical significance was set at 0.05 . To confirm the intra-rater test-retest reliability of the method of strength measurement, intra-class correlation coefficient (ICC) [3, 1] model and 95\% confidence intervals (CIs) were used. Statistical analyses were conducted using PASW statistics 18 (IBM Co., Armonk, NY, USA).

\section{RESULTS}

There were significant differences in the CVA between groups $(p<0.000)$. The strength values of UCE $(p=0.074)$ and LCF ( $p=0.977$ ) were not significantly different between the two groups. The strength values of LCE $(p<0.002)$ and UCF ( $p$ $<0.001)$ were significantly lower in the FHP group than those in the without FHP group (Table 2). The ratio of flexor/extensor strength of upper cervical and lower cervical was shown in a Table 2 .

In the present study, the intra-rater test-retest reliability of

Table 1. Measurement of strength in the UCE, LCE, UCF, and LCF

\begin{tabular}{|c|c|c|}
\hline Measurement & Figure & Instruction \\
\hline Upper cervical extensor & & $\begin{array}{l}\text { The strap is placed on the subject's chin, and the opposite end of the strap is fixed at } \\
\text { the immobile bar located behind the subjects' head. The strength sensor is placed } \\
\text { between the subject and the immobile bar. The subject is indicated to rotate his/her } \\
\text { chin superiorly against the resistance of the strap. }\end{array}$ \\
\hline Lower cervical extensor & & $\begin{array}{l}\text { The strap is placed behind the subject's occipital bone and the opposite end of the } \\
\text { strap is fixed on the immobile bar in front of the subject. The subject is indicated } \\
\text { to move his/her head in a posterior translatory movement while maintaining the } \\
\text { forehead and chin in neutral position. }\end{array}$ \\
\hline Upper cervical flexor & & $\begin{array}{l}\text { The strap is placed below the subject's chin and the opposite end of the strap is fixed at } \\
\text { the immobile bar located over the subject's head at a height } 1 \mathrm{~m} 50 \mathrm{~cm} \text {. The strength } \\
\text { sensor is placed between the subject and the immobile bar. The subject is indicated } \\
\text { to rotate his/her chin inferiorly against the resistance of the strap. }\end{array}$ \\
\hline Lower cervical flexor & & $\begin{array}{l}\text { The strap is placed on the forehead of the subject and the opposite end of the strap is } \\
\text { fixed at the immobile bar located behind the subject's head. The subject is indicated } \\
\text { to rotate his/her forehead in an antero-inferior direction. }\end{array}$ \\
\hline
\end{tabular}

UCE, upper cervical extensor; LCE, lower cervical extensor; UCF, upper cervical flexor; LCF, lower cervical flexor. 
Table 2. The mean values \pm standard deviation of the craniovertebral angle and normalized isometric strength of the cervical muscles in the with FHP group and without FHP group

\begin{tabular}{lccc}
\hline \multicolumn{1}{c}{ Variables } & With FHP $(\mathrm{n}=24)$ & Without FHP $(\mathrm{n}=27)$ & $\mathrm{p}$-value \\
\hline Craniovertebral angle ( ${ }^{\circ}$ ) & $44.8 \pm 2.0$ & $52.5 \pm 3.0$ & $0.000^{*}$ \\
Upper cervical extensor strength (N/kg\%) & $8.8 \pm 3.3$ & $10.6 \pm 3.6$ & 0.074 \\
Lower cervical extensor strength (N/kg\%) & $9.3 \pm 3.7$ & $12.7 \pm 3.7$ & $0.002^{*}$ \\
Upper cervical flexor strength (N/kg) & $7.1 \pm 2.0$ & $9.4 \pm 2.4$ & $0.001^{*}$ \\
Lower cervical flexor strength (N/kg\%) & $5.7 \pm 1.8$ & $5.7 \pm 1.7$ & 0.977 \\
Upper cervical F/E ratio & $0.87 \pm 0.27$ & $0.92 \pm 0.23$ & 0.471 \\
Lower cervical F/E ratio & $0.67 \pm 0.27$ & $0.48 \pm 0.15$ & $0.004^{*}$ \\
\hline
\end{tabular}

FHP, forward head posture; N, Newton; F/E, flexor/extensor. *Represents significant differences.

the Smart KEMA strength sensor was high (ICC > 0.85). The ICC values of the methods of strength measurement ranged from 0.97 to 0.99 . The values (95\% CI) were $0.98(0.97-0.99)$ for UCE, 0.99 (0.98-0.99) for LCE, 0.96 (0.93-0.98) for UCF, and 0.97 (0.95-0.98) for LCF.

\section{DISCUSSION}

Abnormality of postures is considered to exist with muscle imbalance [19]. FHP is typically observed in patients with abnormal posture of the head and neck [20]. The present study compared the difference in the strength of the flexors and extensors of upper and lower cervical region between individuals with and without FHP. The results of the present study demonstrated weakness of the LCE and UCF in the group with FHP, suggesting that extensor muscles should be considered in the management of FHP.

FHP usually involves lengthened cervical flexors, including the longus colli and longus capitis, and is related to deep cervical flexor weakness [7]. The longus capitis and longus colli are the most important muscles involved in the deep cervical flexion movement, and the deep cervical flexors are a part of the UCF anatomically [21]. Bokaee et al. [1] showed that the group with FHP had lower UCF strength than the group without FHP. In addition, change in length of the posterior neck muscles may have an effect on UCF strength. FHP is usually associated with shortening of the suboccipital muscles [3]. Prolonged FHP displays hyperextension of the craniocervical junction [22]. Hyperextension of the craniocervical junction could limit the range of motion during craniocervical flexion, and the limited range of motion could prevent sufficient contraction of the UCF. Thus, the UCF may be weaker in the FHP group than in the without FHP group.

FHP has been described as the flexed position of the lower cervical region [9]. Anatomically, the semispinalis cervicis and cervical multifidus are the LCE muscles that produce an extensor torque in the lower cervical region $[4,5]$. These muscles have a lengthened position in FHP. The load on the cervical muscles caused by head protrusion posture is larger in FHP than in the neutral head position [23], and the LCE produces an eccentric force during flexed posture of lower cervical. Prolonged eccentric contraction could lead to loss of strength [24,25]. This strength loss could be the evidence of our result indicating LCE weakness in the FHP group.

There was no significant difference in the strength of LCF and UCE between the two groups. It is possible that the UCF influenced the measurement of the LCF strength while maintaining the neutral head position. Another possibility is that the flexion movement of the thorax was limited because the upper chest was fixed, and the LCF was not sufficiently mobilized for maximum effort. In the case of UCE, cervical protrusion may have occurred as a compensatory movement. The force of the UCE and cervical protrusion may have combined, such that there was no difference in force between the two groups.

Bokaee et al. [1] compared the ratio of the upper cervical flexor to extensor strength between individuals with and without FHP (1.26 vs. 1.55), and there was significant difference $(p<0.008)$ between groups. In contrast, there was not significantly difference in the ratio of the upper cervical flexor to extensor strength in the present study. In our knowledge, there was little study for comparison of ratio of the upper and lower cervical flexor to extensor strength between individuals with and without FHP. The ratio of the upper cervical flexor to extensor strength could be affected by both the upper cervical flexor and extensor strength. Although significantly difference the ratio of the upper cervical flexor to extensor strength was not found between groups, the upper cervical flexor was 
greater in individuals without FHP than with FHP in the present study. Because of difference of measurement method and instruments, it was difficult to directly compare to the previous study. The ratio of the upper cervical flexor to extensor strength could be controversy.

This study has some limitations. First, we recruited subjects aged 20 to 40 years. Therefore, it is difficult to generalize the results for all ages. Second, it was not clear whether the muscles were activated in each measurement method. Therefore, it is divided by movement, but it is not clear what the target muscles are. For these reasons, further studies will be required to determine whether there is a difference in the cervical muscle strength depending on the presence or absence of pain with the FHP.

\section{CONCLUSIONS}

In this study, we investigated the cervical strength in four directions and compared the strength with and without FHP. Neck strength in the UCF and LCE was significantly lower in the FHP group than in the without FHP group. This study suggests that strength in the LCE as well as the deep neck flexor muscles should be considered to evaluate and manage individuals with FHP.

\section{ACKNOWLEDGEMENTS}

This study was supported by the "Brain Korea 21 FOUR Project”, the Korean Research Foundation for Department of Physical Therapy in the Graduate School of Yonsei University.

\section{CONFLICTS OF INTEREST}

No potential conflict of interest relevant to this article was reported.

\section{AUTHOR CONTRIBUTIONS}

Conceptualization: JYE, OYK, UJH. Data curation: JYE. Formal analysis: JYE, UJH, SHA. Investigation: JYE, UJH, SHJ. Methodology: UJH. Project administration: JYE, OYK. Resources: JYE, SHJ, SHA. Software: UJH, SHJ, SHA. Supervision: OYK, SHA. Validation: JYE. Visualization: JYE. Writing - original draft: JYE, SHJ, SHA. Writing - review \& editing: OYK, UJH, SHJ.

\section{ORCID}

Ji-yeon Eun, https://orcid.org/0000-0002-4146-7534

Ui-jae Hwang, https://orcid.org/0000-0002-2050-5503

Sung-hoon Jung, https://orcid.org/0000-0002-3704-1514

Sun-hee Ahn, https://orcid.org/0000-0001-7660-8598

\section{REFERENCES}

1. Bokaee F, Rezasoltani A, Manshadi FD, Naimi SS, Baghban AA, Azimi H. Comparison of isometric force of the craniocervical flexor and extensor muscles between women with and without forward head posture. Cranio 2016;34(5):286-90.

2. Ruivo RM, Pezarat-Correia P, Carita AI. Effects of a resistance and stretching training program on forward head and protracted shoulder posture in adolescents. J Manipulative Physiol Ther 2017;40(1):1-10.

3. Fernández-de-Las-Peñas C, Cuadrado ML, Pareja JA. Myofascial trigger points, neck mobility, and forward head posture in episodic tension-type headache. Headache 2007;47(5):66272.

4. Patwardhan AG, Khayatzadeh S, Havey RM, Voronov LI, Smith ZA, Kalmanson 0, et al. Cervical sagittal balance: a biomechanical perspective can help clinical practice. Eur Spine J 2018;27(Suppl 1):25-38.

5. Van Wyk L, Jull G, Vicenzino B, Greaves M, O'Leary S. A comparison of craniocervical and cervicothoracic muscle strength in healthy individuals. J Appl Biomech 2010;26(4):400-6.

6. Jung SH, Kwon OY, Choi KH, Ha SM, Kim SJ, Jeon IC, et al. Comparison of the thickness of the neck flexor muscles of subjects with and without a forward head posture on the two initial head positions during cranio-cervical flexion exercise. Phys Ther Korea 2015;22(4):44-50.

7. Son MC, Hwang UJ, Jung SH, Ahn SH, Kim HA, Kwon OY. Comparison of the cross-sectional area of longus colli and muscle activity of sternocleidomastoid in subjects with forward head posture on the two craniocervical flexion methods. Phys Ther Korea 2018;25(2):62-70.

8. Cagnie B, Cools A, De Loose V, Cambier D, Danneels L. Differences in isometric neck muscle strength between healthy controls and women with chronic neck pain: the use of a reliable measurement. Arch Phys Med Rehabil 2007;88(11):1441-5.

9. Kim MH, Yi CH, Kwon OY, Cho SH, Yoo WG. Changes in neck muscle electromyography and forward head posture of chil- 
dren when carrying schoolbags. Ergonomics 2008;51(6):890901.

10. Nojiri K, Matsumoto M, Chiba K, Maruiwa H, Nakamura M, Nishizawa T, et al. Relationship between alignment of upper and lower cervical spine in asymptomatic individuals. J Neurosurg 2003;99(1 Suppl):80-3.

11. Salahzadeh Z, Maroufi N, Ahmadi A, Behtash H, Razmjoo A, Gohari $\mathrm{M}$, et al. Assessment of forward head posture in females: observational and photogrammetry methods. J Back Musculoskelet Rehabil 2014;27(2):131-9.

12. Ylinen J, Salo P, Nykänen M, Kautiainen H, Häkkinen A. Decreased isometric neck strength in women with chronic neck pain and the repeatability of neck strength measurements. Arch Phys Med Rehabil 2004;85(8):1303-8.

13. van Niekerk SM, Louw Q, Vaughan C, Grimmer-Somers K, Schreve K. Photographic measurement of upper-body sitting posture of high school students: a reliability and validity study. BMC Musculoskelet Disord 2008;9:113.

14. Lee KJ, Han HY, Cheon SH, Park SH, Yong MS. The effect of forward head posture on muscle activity during neck protraction and retraction. J Phys Ther Sci 2015;27(3):977-9.

15. Yip $\mathrm{CH}$, Chiu TT, Poon AT. The relationship between head posture and severity and disability of patients with neck pain. Man Ther 2008;13(2):148-54.

16. Candan SA, Sahin UK, Akoğlu S. The investigation of workrelated musculoskeletal disorders among female workers in a hazelnut factory: prevalence, working posture, work-related and psychosocial factors. Int J Ind Ergon 2019;74:102838.

17. Kim HA, Hwang UJ, Jung SH, Ahn SH, Kim JH, Kwon OY. Effect of horizontal adduction force on infraspinatus and deltoid activities during the side-lying wiper exercise using pressure biofeedback. Phys Ther Korea 2017;24(4):77-83.

18. O'Leary S, Fagermoen CL, Hasegawa H, Thorsen AS, Van Wyk L. Differential strength and endurance parameters of the craniocervical and cervicothoracic extensors and flexors in healthy individuals. J Appl Biomech 2017;33(2):166-70.

19. Lewis JS, Green A, Wright C. Subacromial impingement syndrome: the role of posture and muscle imbalance. J Shoulder Elbow Surg 2005;14(4):385-92.

20. Kim SY, Kim NS, Kim LJ. Effects of cervical sustained natural apophyseal glide on forward head posture and respiratory function. J Phys Ther Sci 2015;27(6):1851-4.

21. Falla DL, Campbell CD, Fagan AE, Thompson DC, Jull GA. Relationship between cranio-cervical flexion range of motion and pressure change during the cranio-cervical flexion test. Man Ther 2003;8(2):92-6.

22. Yuill E, Howitt SD. Temporomandibular joint: conservative care of TMJ dysfunction in a competitive swimmer. J Can Chiropr Assoc 2009;53(3):165-72.

23. Edmondston SJ, Sharp M, Symes A, Alhabib N, Allison GT. Changes in mechanical load and extensor muscle activity in the cervico-thoracic spine induced by sitting posture modification. Ergonomics 2011;54(2):179-86.

24. Warren GL, Ingalls CP, Lowe DA, Armstrong RB. What mechanisms contribute to the strength loss that occurs during and in the recovery from skeletal muscle injury? J Orthop Sports Phys Ther 2002;32(2):58-64.

25. Hubal MJ, Rubinstein SR, Clarkson PM. Mechanisms of variability in strength loss after muscle-lengthening actions. Med Sci Sports Exerc 2007;39(3):461-8. 